\title{
UMA ANÁLISE SOBRE DIREITO, SUSTENTABILIDADE E GOVERNANÇA, VISTA DE UM PRISMA MARXISTA, SOB A INFLUÊNCIA DO CAPITAL NA DETERIORIZAÇÃO PROGRESSIVA DO MEIO AMBIENTE
}

Antonio Augusto Vilela

ISSUE DOI: $10.21207 / 1983.4225 .242$

\section{RESUMO}

O presente trabalho consiste em um estudo bibliográfico sobre Direito, sustentabilidade e governança. A principal finalidade desse trabalho foi apreciar os aspectos histórico e filosófico da proporcionalidade da degradação ambiental, dando destaque para uma análise marxista, sobre o quanto o capital influencia na deteriorização progressiva do meio ambiente, em virtude da classe social dominante em relação à classe dominada. Abordam-se os fatores que contribuem para a degradação, observando-se a não garantia do bem comum, tendo em vista que todos os homens deveriam ter seus Direitos Constitucionais respeitados, já que o Estado é quem promove a satisfação desses Direitos e Garantias. Elevam-se esses fatores, em relação aos quais selecionam-se os mais importantes para a formação de um meio ambiente digno, no qual certamente se almeja a so- 
brevivência em um cenário amplo repleto de particularidades a serem observadas constantemente. Julgando a partir dessa finalidade, ou seja, desse objetivo, destaca-se a relevância dos limites ambientais, que por meio de transformações, como por exemplo, a busca cada vez maior feita pelo homem por riquezas naturais, que permite uma garantia abstrata de melhor qualidade de vida para certos indivíduos. Assim, é essencial destacar que a garantia constitucional de um meio ambiente satisfatório não se passa apenas por ser uma garantia abstrata e que dá simplesmente uma certa esperança aos homens. Além disso, expressa, em sua maior parte, apenas o contentamento a certo grau de satisfação de pouca parte dos cidadãos. Portanto, esses resultados, sem dúvida alguma, demonstram que a sistematização do Estado possui um paradigma muito grande, que deve ser observado e modificado constantemente, atendendo aos anseios sociais.

Palavras-chave: Crítica. Direitos. Homens. Meio ambiente.

\section{INTRODUÇÃO}

Um dos principais fatores para a existência do homem no mundo é a sua relação com o meio ambiente, visando à produção de valores de uso. O que garante que o meio ambiente não seja deteriorado progressivamente é o modo de produção, que caracteriza a infra e a superestrutura social. No Brasil, a Legislação de Direito Ambiental protege e dá garantias abstratas ao meio ambiente, mas nem sempre essas garantias/normas têm sido cumpridas a contento.

Marques enfatiza que:

A recente avaliação do estado do ambiente do planeta, realizada pelo Programa das Nações Unidas para o Ambiente (PNUA), que envolveu cerca de 1500 cientistas e peritos de todo o Mundo, apenas confirmou o que já se sabia: que a ação humana é responsável pela destruição do ambiente no planeta e dos seus recursos naturais, verificando-se uma quebra assustadora da biodiversidade terrestre, aquática e humana. As pressões exercidas sobre as funções naturais do planeta ao longo do último século são de tal ordem e dão-se a um ritmo tal, que 
a capacidade de recuperação dos ecossistemas se encontra severamente comprometida, ameaçando a própria sobrevivência humana, em um futuro não muito longínquo. ${ }^{1}$

Nesse contexto, ainda se observa que, no Brasil, devido à riqueza de seu solo e de seu subsolo, as principais atividades econômicas são responsáveis pela degradação do meio ambiente: poluição da água (esgotos), poluição do ar (emissão de dióxido de enxofre, monóxido de carbono, óxido e dióxido de nitrogênio e de material particulado, como poeira, fumaça e fuligem, crescem em todas as aglomerações urbanas) e lançamento de agrotóxicos (DDT, inseticidas, pesticidas); todos esses tipos de poluição envolvem grandes poderes econômicos empresariais, que exploram os trabalhadores e o meio ambiente.

Pela amplitude do tema, buscou-se analisar a relação entre a manutenção do Estado e a instituição da propriedade privada dos meios de produção, com os interesses sociais capitalistas e a divisão desigual das riquezas produzidas, uma vez que ela está regulamentada de acordo com a legislação que garante ao meio ambiente, abstratamente, a sua menor degradação.

O meio ambiente necessita de uma observação cada vez mais acurada, pois a busca particularizada de riquezas para ampliar o capital e a destruição desordenada dos meios de subsistência pelo homem são fatores que levam a refletir sobre o que fazer para conservar o meio ambiente. A conscientização dos indivíduos e o fator governamental, essencial para a conservação do meio, grande parte das vezes deixam toda a degradação acontecer sem nenhuma sanção. Isso faz com que a divisão desigual da renda beneficie os grandes empresários, esquecendo do fator essencial, que é a história do homem e da luta contra a natureza e a conservação integral do meio ambiental, que passará de gerações a gerações.

\section{FUNDAMENTAÇÃO TEÓRICA}

1 Malheiros,1992. p. 383. MARQUES, Jose Alberto. Sustentabilidade: temas fundamentais de direito ambiental. Campinas - SP: Millennium, 2009. p. 02. 


\subsection{Definição de direito, sustentabilidade, governança e capital}

A definição de Direito vem do romano jus, que significa a busca de aperfeiçoamento das qualidades sociais ao indicar e instituir normas lícitas e equitativas de procedimento dos indivíduos. ${ }^{2}$

O direito ainda está relacionado com o jus do latim clássico, tendo assim o mesmo significado dos termos justiça, justo, jurídico, judiciário, judicial etc. ${ }^{3}$

Mascaro ainda ressalta que:

Durante muito tempo, chamou-se por direito aquilo que hoje chamaríamos por religião, ou mesmo por política. Quem dirá que os Dez Mandamentos são um monumento jurídico? Mas quem poderá dizer que são um conjunto de normas só religiosas e não jurídicas? $\mathrm{Na}$ verdade, em sociedades do passado, como a hebreia, não há algo que, especificamente, seja chamado por direito, e que seja totalmente distinto da religião, por exemplo. ${ }^{4}$

No que diz respeito à sustentabilidade, o Direito deve agir com a finalidade de evitar que a exploração do meio ambiente seja feita de maneira irracional, exigindo dos exploradores e os responsabilizando, caso o conceito de sustentabilidade seja violado.

A conceituação de sustentabilidade está ligada diretamente ao desenvolvimento, que satisfaz as necessidades do meio ambiente atual sem afetar a capacidade das gerações futuras satisfazerem as suas próprias necessidades.

Silva enfatiza que:

\footnotetext{
${ }^{2}$ VENOSA, Silva de Salvo. Introdução ao estudo do direito: primeiras linhas. 2.ed. São Paulo: Atlas, 2008. p. 09.

${ }^{3}$ VENOSA, Silva de Salvo. Introdução ao estudo do direito: primeiras linhas. 2.ed. São Paulo: Atlas, 2008. p. 11.

4 MASCARO, Alysson Leandro. Lições de Sociologia do Direito. 2. ed. São Paulo: Quartier Latin, 2009. p. 10.
} 
Isso nos põe diante da necessidade de fazer algumas considerações sobre a sustentabilidade. E podemos começar mostrando que esse é um conceito que tem fundamentos constitucionais, pois o art.225 da $\mathrm{CF}$ impõe ao Poder Publico e à coletividade o dever de defender e preservar o direito ao meio ambiente ecologicamente equilibrado "para as presentes e futuras gerações", precisamente dando o conteúdo essencial da sustentabilidade. ${ }^{5}$

Os indivíduos ainda se encontram cada vez mais complexos e os valores econômicos sufocam o valores éticos, culturais e humanos, gerando uma corrida desenfreada ao enriquecimento fácil e desrespeitador da utilização, da exploração e da gestão racional dos recursos finitos, em que a competição, o egoísmo, o desprezo e desrespeito pelo outro são fatores que sobressaem em um sociedade e estimulam progressivamente a degradação do meio. ${ }^{6}$

Por sua vez, os capitalistas, que são diretamente interessados na exploração do meio ambiente, não adotam, ao pé da letra, medidas sustentáveis; basta observarmos a degradação de matas nativas para o avanço de suas atuações e a destruição generalizada da superfície do planeta.

O conceito de governança está ligado diretamente às estratégias para controlar e determinar um desempenho organizacional satisfatório, ainda que nesse contexto se observe que o aparecimento do termo governance inicia-se quando surgem as ideias administradas especialmente pelo Banco Mundial, "tendo em vista aprofundar o conhecimento das condições que garantem um Estado eficiente". ${ }^{7}$

Como o interesse ávido pelo capital transcende os limites do respeito à vida, o sistema capitalista degrada e destrói, com o intuito de acumular riquezas.

Marx ressalta que:

\footnotetext{
${ }^{5}$ SILVA, Jose Afonso da. Direito Ambiental Constitucional. 8.ed. São Paulo:PC, 2010. p. 25.

${ }^{6}$ MAY, Peter H.; LUSTOSA, Maria Cecilia; VINHA, Valeria da. Economia do meio ambiente : teoria e prática. 4. ed. Rio de Janeiro: Elsevier, 2003. p. 03.

7 DINIZ, Eli. Governabilidade, Democracia e Reforma do Estado: Os desafios da Construção de uma Nova Ordem no Brasil dos Anos 90. In: DADOS - Revista de

Ciências Sociais. Rio de Janeiro, volume 38, n³, 1995. p. 400.
} 
A circulação das mercadorias é o ponto de partida. A produção de mercadorias e o comércio, forma desenvolvida da circulação de mercadorias, constituem as condições históricas que dão origem ao capital. Se pusermos de lado o conteúdo material da circulação das mercadorias, a troca do diferentes valores de uso, para considerar apenas as formas econômicas dadas por esse processo de circulação, encontraremos o dinheiro como produto final. Esse produto final da circulação das mercadorias é a primeira forma em que aparece o capital. ${ }^{8}$

O conceito de capital está relacionado ao valor monetário empregado em um determinado modo de produção; converte-se, por um lado, em meios de produção (matéria-prima) e, por outro, em força de trabalho, em que se reproduz seu próprio equivalente e também excedente, que se caracteriza como mais valia. Neste contexto, Rocha afirma que o conceito de capital é "fundo de bens ou dinheiro".?

Sendo a governança a gestão de empresas, sejam elas estatais ou particulares, cabe ao Estado uma eficácia maior tanto na área de fabricação de leis quanto na área de fiscalização, para que a sustentabilidade não passe de uma mera especulação da mídia e passe a ser de fato um fruto da conscientização humana para a preservação do meio ambiente equilibrado.

\section{CAPITALISMO E QUESTÃO AMBIENTAL}

Em nossas vidas, a questão ambiental tem ocupado um espaço cada vez maior. Isso se deve não só ao surgimento de movimentos em defesa do chamado mundo verde, como também aos anúncios, cada vez mais frequentes, que tentam vender qualidade de vida. As iniciativas da mídia em nos alertar para o avanço dos processos de degradação das áreas de vegetação nativa, as mudanças climáticas, a aceleração das perdas de

\footnotetext{
${ }^{8}$ MARX, Karl. O capital. Trad. Ronaldo Alves Schmidt. 5. ed. Rio de Janeiro: Zahar, 1978. p. $165-166$.

${ }^{9}$ ROCHA, Ruth. Minidicionário. São Paulo: Scipione, 1996. p. 118.
} 
solo por erosão e as crescentes perdas de biodiversidade dão a dimensão do quanto estamos diante de algo que ameaça a vida no planeta.

Segundo May, Lustosa e Vinha,

Em relação aos recursos naturais, só muito recentemente os agentes econômicos passaram a sofrer restrições em relação à forma como os vinham usando. Ainda assim, como foi visto, essas restrições regulatórias se concentraram fundamentalmente sobre aquelas atividades cujos efeitos degradantes atingiam a qualidade de vida das populações em seus locais de origem. A aceitação, por parte dessas populações (concentrada nos países afluentes), de restrições ambientais que envolvam algum tipo de sacrifício em benefício de populações de outros países e/ou de um futuro longínquo implica, forçosamente, uma certa dose de altruísmo. ${ }^{10}$

Todos, independentemente do estrato social a que pertencem, incorporam a defesa da Natureza, do combate à degradação ambiental, a ponto de se perceber a emergência de um modismo em prol da defesa do verde. ${ }^{11}$

Em geral, todos defendem o que chamamos de "desenvolvimento sustentado", um modelo de desenvolvimento fundamentado na ideia de que os recursos naturais sejam explorados de modo a minimizar os impactos negativos sobre os sistemas naturais e sobre as sociedades (o que inclui as futuras gerações). ${ }^{12}$

Além da simples vontade, é preciso que as pessoas se conscientizem a respeito da necessidade de ir fundo na busca das raízes do problema, ou seja, antes de limpar o meio ambiente é preciso que primeiro limpemos nossas ideias, e ir fundo significa ir além da simples concepção de que o homem está destruindo o planeta Terra. ${ }^{13}$

\footnotetext{
${ }^{10}$ MAY, Peter H.; LUSTOSA, Maria Cecília; VINHA, Valéria da. Economia do meio ambiente : teoria e prática. 4. ed. Rio de Janeiro: Elsevier, 2003. p. 15.

${ }^{11}$ Idem. p. 05.

${ }^{12}$ Ibidem.

${ }^{13}$ Ibidem.
} 
A substituição da produção de caráter manufatureiro e artesanal por uma produção em série, com alto grau de especialização do operariado e uso de máquinas cada vez mais potentes, elevou significativamente a produtividade e a produção de bens de consumo em um número de indústrias cada vez maior. A produção, para simplesmente atender às necessidades de consumo do homem, tem por propósito promover a acumulação capitalista. ${ }^{14}$

A busca incessante por crescentes quantidades de matériasprimas e energia em todo o mundo, associada à necessidade de baixar ao máximo os custos de produção, acabou por deixar os sistemas naturais expostos a todo tipo de destruição.

A lógica do capitalismo ainda impacta de outra maneira sobre os sistemas naturais, as múltiplas estratégias utilizadas por grandes empresários (os capitalistas) para que avalanches de produtos industrializados e serviços possam ser incessantemente consumidos. Nesse sentido, o sistema capitalista precisou alicerçar-se no estímulo a um consumismo desenfreado. Criou-se uma ideia de que as necessidades do homem são ilimitadas, o que justifica a busca pelo ilimitado crescimento do consumo de bens e serviços por parte das sociedades consumistas. ${ }^{15}$

O consumo sem limites, dentro dos moldes de produção capitalista, dá margem à produção de resíduos tóxicos dos mais diversos, que, em grande medida, recebem um destino inadequado, afetando ambientes hídricos, o solo e o próprio ar atmosférico.

A degradação deve ser entendida como uma doença universal, presente tanto nos países centrais como nos periféricos do capitalismo. Nos primeiros, temos um contato maior com o que muitos denominam poluição direta, que representa as transformações ambientais produzidas por um modelo de produção e consumo capitalista. Nos outros países, além da presença da poluição direta, encontramos também uma "poluição indireta", representada pela fome, pela miséria, pela péssima distribuição da renda, pelo endividamento externo, pela precária escolaridade das populações etc. Nesse último caso, temos uma forma de poluição chamada subdesenvolvimento, resultado do modelo desenvolvimentista imposto

\footnotetext{
${ }^{14}$ MAY, Peter H.; LUSTOSA, Maria Cecília; VINHA, Valéria da. Economia do meio ambiente : teoria e prática. 4. ed. Rio de Janeiro: Elsevier, 2003. p. 07.

15 Idem. p. 09.
} 
pelos países de centro do capitalismo e irresponsavelmente aceito pelas elites dos países periféricos. ${ }^{16}$

A questão ambiental é, antes de tudo, uma questão política e econômica, uma vez que o enfrentamento do problema passa por uma total reviravolta na política econômica que rege o mundo, de tais modos a possibilitar a diminuição do fosso que separa os poucos países ricos dos muitos países pobres. E, dentro desses países, entre aqueles que concentram a riqueza e aqueles que amargam a exclusão em elevados níveis.

\section{3 \\ O DESENVOLVIMENTO DO CAPITALISMO E A AMPLIAÇÃO DA DEGRADAÇÃO DO MEIO AMBIENTE}

No início da sociedade, quando o ser humano tinha diante de si apenas a imensidão das florestas, a terra era vasta e a indústria mal começava a nascer, a terra ainda não era modificada pelo trabalho, era um objeto de utilidade; não era necessariamente um valor de troca, era um bem comum, não social. Pouco a pouco, com o progresso da agricultura, o trabalho veio dar ao solo seu valor comercial. Nascia, assim, a renda, que, em suma, é o ponto de partida do capitalismo. Queremos abordar a partir deste ponto o seu desenvolvimento e a degradação do meio ambiente. ${ }^{17}$

Com o advento da Revolução Industrial, a sociedade humana e o meio ambiente começaram a sofrer uma série de mudanças radicais, que deram início a uma exploração acentuada não só do homem pelo próprio homem, mas também uma transformação gradativa do planeta. Enormes continentes de terra passaram a pertencer a um número reduzido de exploradores, que, utilizando a força de trabalho do homem, começaram a produzir e a destruir em larga escala. ${ }^{18}$

Dessa forma, o capitalismo tomou força, com o auxílio de máquinas sofisticadas; o solo, que teria como finalidade a subsistência comum das pessoas, passou a ser fonte de riqueza, e, em decorrência da

\footnotetext{
${ }^{16}$ MAY, Peter H.; LUSTOSA, Maria Cecilia; VINHA, Valeria da. Economia do meio ambiente : teoria e prática. 4. ed. Rio de Janeiro: Elsevier, 2003. p. 12.

${ }^{17}$ Idem. p. 14.

${ }^{18}$ Idem. p. 15.
} 
ganância, os grandes produtores defasaram os recursos naturais para garantir a obtenção de lucro. ${ }^{19}$

Nesse ínterim, segundo Marx, "a relação do homem com a natureza é função das relações estabelecidas pelos homens e entre os homens em um dado modo de produção"20. O modo de produção capitalista é um progresso na arte de esgotar o solo e explorar o homem.

Na percepção de Singer,

Quando se fala de "capitalismo", pensa-se em capital e sobretudo em capitalista, sujeito rico, poderoso, em geral dono ou dirigente de empresa industrial, comercial ou banco. Mas "capitalismo" sugere também enorme variedade de produtos que são estridentemente propagandeados pelos meio de comunicação em massa. Os símbolos atuais deste aspecto capitalista talvez sejam o automóvel e principalmente a televisão, que é meio de consumo e veículo de publicidade ao mesmo tempo. ${ }^{21}$

Por ser um sistema constitucionalmente explorador, destruidor e desigual, em que uma classe dominadora é detentora dos meios de produção e das riquezas produzidas, o capitalismo se desenvolve de uma forma paradoxal em que a economia marxista percebe e analisa as contradições do sistema. Em alguns casos, há grande produção, mas falta poder de compra por parte dos trabalhadores, e o prejuízo não é sentido somente nas relações sociais, mas também no que diz respeito ao próprio meio ambiente.

Faladori enfatiza que:

A partir da análise de Marx, podemos entender que o problema social e político é sempre anterior ao das possíveis barreiras físicas. É assim que, na sociedade

${ }^{19}$ MAY, Peter H.; LUSTOSA, Maria Cecilia; VINHA, Valeria da. Economia do meio ambiente : teoria e prática. 4. ed. Rio de Janeiro: Elsevier, 2003. p. 17.

${ }^{20}$ MARX, Karl. O capital. Trad. Ronaldo Alves Schmidt. 5. ed. Rio de Janeiro: Zahar, 1978. p. 42.

${ }^{21}$ SINGER, Paul. O capitalismo : sua evolução, sua lógica e sua dinâmica. São Paulo: Moderna, 1987. p. 07. 
capitalista, enormes volumes de alimentos são desperdiçados anualmente quando seus preços não chegam a cobrir os custos de produção. Enquanto isso, milhões de pessoas morrem de fome. A contradição entre o valor de uso e o valor das mercadorias, que é o ponto de partida da exposição marxista do capitalismo, é também a origem do entendimento dessas contradições. ${ }^{22}$

Do ponto de vista estritamente socioecológico, percebe-se que os problemas são resultantes do modo da produção capitalista, pelo fato de o desenvolvimento da economia capitalista concentrar-se na extração ilimitada dos recursos naturais e na exploração da força de trabalho humana, da natureza e do operário, simultaneamente.

Enfim, conclui-se que o capitalismo não é só um câncer social, mas também uma força destruidora ativa, que faz do planeta Terra o quintal de um grupo reduzido de pessoas irresponsáveis que, para garantir sua riqueza, exploram o homem e degradam cada vez mais o meio ambiente, assegurando-se de seu dinheiro conseguido de forma desleal. O capitalismo é um roubo e o capitalista, o ladrão.

\section{DIREITO, ESTADO E QUESTÃO AMBIENTAL NO BRASIL}

Um dos problemas mais graves do Brasil diz respeito aos impactos ambientais, visto que nosso País é beneficiado com a maior biodiversidade mundial. Conforme enfatiza Brito,

Os sistemas nacionais de áreas naturais protegidas devem ser estabelecidos de forma a melhor representar a biodiversidade dos países e a responder aos requerimentos para a sua conservação, objetivando ao desenvolvimento humano

sustentável. $\mathrm{O}$ estabelecimento desses sistemas

${ }^{22}$ FOLADORI, Guillermo. A questão ambiental em Marx. In Revista Crítica Marxista, n. 04. p. 140 - 161. São Paulo: Xamã, 1997. p.146. 
permite ao País avaliar seu grau de compromisso para com a conservação. ${ }^{23}$

A natureza sofre desde o inicio da colonização, quando nosso litoral foi devastado pelos colonizadores. Matas foram derrubadas, animais foram mortos. Esses estragos se estenderam ao interior e romperam o equilíbrio ecológico. ${ }^{24}$

Atualmente, a preocupação com a proteção ao meio ambiente ocupa lugar de destaque entre aquelas de maior importância para toda a sociedade. Cada vez mais se voltam as atenções para a inviabilidade da ideia de explorar os bens naturais como se fossem inesgotáveis.

Influenciado pela primeira Conferência das Nações Unidas sobre o Meio Ambiente Humano, realizada em Estocolmo (Suécia), no ano de 1972, o governo brasileiro, anos depois, em 1981, passou a dispor de um instrumento legal de proteção ao meio ambiente: a Lei ${ }^{\circ} 6.938$, denominada Lei da Política Nacional do Meio Ambiente, em vigor até hoje.

A Lei, além de objetivar a preservação, a melhoria e a recuperação da qualidade ambiental, visa também a assegurar o desenvolvimento econômico, mas com racionalidade de uso dos recursos naturais. Foi um grande avanço, principalmente numa época em que a visão era a de desenvolvimento a qualquer preço.

Essa mesma lei estabeleceu a criação do Sisnama (Sistema Nacional de Meio Ambiente), formado por dois órgãos: o Conama (Conselho Nacional do Meio Ambiente), que é o órgão superior do sistema, cuja função é assessorar a presidência da República, e o Seman (Secretaria do Meio Ambiente da Presidência da República), sendo esse o órgão central do sistema vinculado ao Ibama (Instituto Brasileiro do Meio Ambiente e dos Recursos Naturais Renováveis), criado em 1989.

O Art. 225, da Constituição do Brasil de 1988, coloca a questão ambiental na forma que se segue: "Todos têm direito a um meio ambiente ecologicamente equilibrado, bem de uso comum do povo e essencial à sadia qualidade de vida, impondo-se ao Poder Público e à coletividade o dever de defendê-lo e preservá-lo para as presentes e futuras gerações."

${ }^{23}$ BRITO, Maria Cecilia Wey de. Unidades de conservação : intenção e resultados. 2. ed.. São Paulo : Annablume : Fapesp, 2003. p. 35.

${ }^{24}$ MAY, Peter H.; LUSTOSA, Maria Cecilia; VINHA, Valeria da. Economia do meio ambiente : teoria e prática. 4. ed. Rio de Janeiro: Elsevier, 2003. p. 20. 
Vale destacar que a legislação brasileira é considerada avançada em muitos aspectos, no entanto apresenta um caráter brando do ponto de vista penal. Vários crimes cometidos contra o meio ambiente ficam impunes devido ao pequeno número de fiscais em relação à extensão do território brasileiro. ${ }^{25}$

Percebe-se que, embora a Constituição de 1988 signifique um avanço na legislação e gestão administrativa pública socioambiental do País, o caminho ainda é longo e está em constante construção. Enquanto não houver conscientização política das e nas coletividades, não haverá cobrança de direitos.

\section{CONSIDERAÇÕES FINAIS}

Para finalizar este trabalho, foi proposta uma análise embasada em concepções marxistas e estritamente anticapitalistas, e verificou-se o quanto esse sistema vil e sórdido é nocivo não só para o homem como ser social, mas também para o meio ambiente, em decorrência do seu grande potencial destrutivo.

Percebe-se que a crise ambiental é decorrente das sucessivas crises do capitalismo que se representam diretamente no seio da sociedade, tomando proporções em escala global devido à grande interdependência dos países, que faz com que os abundantes em matéria-prima explorem seus recursos naturais, sem uma devida preocupação com o equilíbrio ambiental.

Políticas de conscientização quanto à proteção ao meio ambiente e as leis que tentam reduzir o impacto ambiental causado pela exploração desenfreada e irresponsável do meio ambiente têm sido criadas, mas sua eficácia é deficiente pela falta de estrutura do Estado e também pela grande influência do capital, que é resultante do processo de circulação de mercadorias, tendo valores agregados de acordo com o seu processo de conversão em valores de uso. De fato o homem moderno está excessivamente ligado à base material/econômica da sociedade, a qual Karl Marx denomina de infraestrutura; assim sendo, grande parte dos indivíduos

\footnotetext{
${ }^{25}$ MAY, Peter H.; LUSTOSA, Maria Cecilia; VINHA, Valeria da. Economia do meio ambiente : teoria e prática. 4. ed. Rio de Janeiro: Elsevier, 2003. p. 26.
} 
usam a supraestrutura, que é uma ideologia, para justificar a dominação dos meios.

Enfim, é de suma importância que as questões ambientais sejam de fato analisadas com cuidado não só pelos indivíduos, mas também por parte do Estado, e a consciência ecológica não continue sendo uma especulação da mídia, passando a ser verdadeiramente considerada como uma questão primordial para a própria sobrevivência da espécie humana.

\section{REFERÊNCIAS}

BRITO, Maria Cecilia Wey de. Unidades de conservação : intenção e resultados. 2. ed.. São Paulo : Annablume : Fapesp, 2003.

BUCCI, Maria Paula Dollari. Direito administrativo e políticas públicas. São Paulo: Saraiva, 2002.

CHIAVENTO, Idalberto. Planejamento Estratégico. 2.ed. Rio de Janeiro: Elsevier, 2003.

DINIZ, Eli. Governabilidade, Democracia e Reforma do Estado: Os desafios da Construção de uma Nova Ordem no Brasil dos Anos 90. In: DADOS - Revista de Ciências Sociais. Rio de Janeiro, volume $38, \mathrm{n}^{\circ} 3,1995$.

FOLADORI, Guillermo. A questão ambiental em Marx. In Revista Crítica Marxista, n. 04. p. 140-161. São Paulo: Xamã, 1997. p.146.

MAGRINI, Alessandra. Gestão Ambiental. PPE/ COp.p.E/ UFRJ, 2001.

MARQUES, Jose Alberto. Sustentabilidade: temas fundamentais de direito ambiental. Campinas - SP: Millennium, 2009.

MARX, Karl. O capital. Trad. Ronaldo Alves Schmidt. 5. ed. Rio de Janeiro: Zahar, 1978.

MASCARO, Alysson Leandro. Lições de Sociologia do Direito. 2. ed. São Paulo: Quartier Latin, 2009.

MAY, Peter H.; LUSTOSA, Maria Cecilia; VINHA, Valeria da. Economia do meio ambiente : teoria e prática. 4. ed. Rio de Janeiro: Elsevier, 2003.

ROCHA, Ruth. Minidicionário. São Paulo: Scipione, 1996.

SEVERINO, Antonio Joaquim. Metodologia do trabalho cientifico. 20. ed. São Paulo: Cortez, 1996.

SILVA, Jose Afonso da. Direito Ambiental Constitucional. 8.ed. São Paulo:PC, 2010. 
SINGER, Paul. O capitalismo : sua evolução, sua lógica e sua dinâmica. São Paulo: Moderna, 1987.

SITE,

Recursos

Ambientais.

<http://geopraticando.blogspot.com/2011/09/o-estado-brasileiro-equestao-ambiental.html>. Acesso em 02/09/2013 - às 7:22.

VENOSA, Silva de Salvo. Introdução ao estudo do direito: primeiras linhas. 2.ed. São Paulo: Atlas, 2008. 
